\title{
Fortification of chocolate using Moringa oleifera extract encapsulated in microemulsions
}

\author{
Olga Kaltsa, Aggeliki Alibade, Georgia Batra, Eleni Bozinou, Dimitris P. Makris and Stavros I. Lalas* \\ Department of Food Science \& Nutrition, University of Thessaly, Terma N. Temponera Street, GR-43100 Karditsa, Greece
}

Received 8 February 2021 - Accepted 24 June 2021

\begin{abstract}
The aim of the present study was to evaluate the physical and antioxidant properties of microemulsions containing Moringa oleifera leaf extract (MLE) produced by the means of a deep eutectic solvent. Selected microemulsions containing MLE were incorporated in chocolate products to enrich them. Their color properties including CIE L*, $\mathrm{a}^{*}, \mathrm{~b}^{*}$ parameters and whitening index (WI) along with DPPH radical scavenging activity were assessed during a period of 8 months. The antioxidant activity of microemulsions depended on the oil phase used, while it was unaffected by the concentration of MLE. Samples prepared with soybean oil as oil phase containing MLE presented the highest radical inhibition percentage $(\mathrm{I} \%=26.8-27.8 \%)$. Coconut microemulsions were finally incorporated at 2 and $4 \% \mathrm{w} / \mathrm{w}$ concentration into chocolate products, as coconut oil is a known cocoa butter substitute. Although the incorporation of MLE microemulsions did not affect the color properties of most of the chocolates, enriched products did not exhibit superior antioxidant activity compared to control samples.
\end{abstract}

Keywords: Moringa oleifera / chocolate / microemulsion / stability / antioxidant capacity

Résumé - Fortification du chocolat à l'aide d'un extrait de Moringa oleifera encapsulé dans des microémulsions. L'objectif de cette présente étude était d'évaluer les propriétés physiques et antioxydantes de microémulsions contenant de l'extrait de feuille de Moringa oleifera (MLE) produit avec un solvant eutectique profond. Les microémulsions sélectionnées contenant du MLE ont été incorporées dans des produits chocolatés pour les enrichir. Leurs propriétés de couleur, y compris l'espace chromatique CIE L*, $a^{*}, b^{*}$ et l'indice de blanchiment (WI), ainsi que l'activité de piégeage des radicaux DPPH, ont été évaluées durant une période de 8 mois. L'activité antioxydante des microémulsions dépendait de la phase huileuse utilisée, alors qu'elle n'était pas affectée par la concentration de MLE. Les échantillons préparés avec de l'huile de soja comme la phase huileuse contenant du MLE ont présenté le pourcentage le plus élevé d'inhibition des radicaux $(I \%=26,8$ $27,8 \%$ ). Les microémulsions de noix de coco ont finalement été incorporées à des concentrations de 2 et $4 \%$ (en masse) aux produits chocolatés, l'huile de noix de coco étant un substitut connu du beurre de cacao. Bien que l'incorporation des microémulsions MLE n'ait pas affecté les propriétés de couleur de la plupart des chocolats, les produits enrichis n'ont pas présenté une activité antioxydante supérieure à celle des échantillons témoins.

Mots clés : Moringa oleifera / chocolat / microémulsion / stabilité / capacité antioxydante

\footnotetext{
*Correspondence: slalas@uth.gr
} 


\section{Highlights}

- Deep eutectic solvent extract was incorporated in food grade micro-emulsions.

- Microemulsions were stable against centrifugation and thermal treatment.

- Microemulsion antioxidant activity was greater for soybean oil formulations.

- Microemulsion incorporation in chocolate products did not impose a significant antioxidant effect.

\section{Introduction}

Food bio-functionality improvement is considered as an established priority for the food industry. To help achieve the production of healthier food, numerous techniques and methodologies have been developed within the last couple decades following the nutrient fortification (Akhtar et al., 2011; Shilpashree et al., 2015; Zhu et al., 2020) or encapsulation path when components sensitive to processing (i.e., vitamins, antioxidants, enzymes, probiotics) are incorporated (Ye et al., 2018; Maurya et al., 2020; Castro Coelho et al., 2021). For the encapsulation of bioactive ingredients, several technologies have been proposed including nano/microemulsification, spray drying, lyophilization, electro-spinning/ spraying (Ray et al., 2016; Jalali-Jivan et al., 2020; Moreira et al., 2020). However, micro-emulsions are considered more advantageous than nano-emulsions since they are transparent and therefore do not affect the appearance of food products nor they require expensive equipment or ingredients for their formation (Flanagan and Singh, 2006; McClements, 2018).

Moringa oleifera seed and leaf extracts (MLE) have recently drawn attention for food and medicinal applications mainly due to high levels of antioxidants that can act protectively against the oxidative stress of cells (Lalas and Tsaknis, 2002; Karageorgou et al., 2017; Soliman et al., 2020). These include phytochemicals such as glucosinolate, ascorbic acids, carotenoids, phenolic acids and flavonoids (Dhakad et al., 2019). Although the chemical consistency and antioxidant properties of MLE have been well documented (Lin et al., 2018; Suresh et al., 2020; Syeda and Riazunnisa, 2020; Wang et al., 2020) etc., there are limited studies on encapsulation of MLE in microemulsions (Batra et al., 2017; Sermkaew and Plyduang, 2020), as well as an absence of studies with regards to possible application in food.

In recent years, food production processes have prioritized the adaptation of technologies that minimize the impact to the environment. Deep eutectic solvents (DES) are a neoteric class of liquids that can be composed easily using affordable food grade compounds (polyols such as glycerol, organic acid salts and amines). Their main advantages include feasibility of tailor-made properties, preparation simplicity, absence of flammability, biodegradability and low toxicity. These characteristics make them suitable solvents for use in extraction of antioxidant compounds like polyphenols (Lakka et al., 2020).

Therefore, the main objective of this work was to examine the properties of MLE microemulsions formed with a natural deep eutectic solvent (NADES) and examine the effect of its addition in chocolate products to enhance their antioxidant capacity.

\section{Material and methods}

\subsection{Materials}

1, 1-diphenyl-2-picryl-hydrazyl (DPPH) reagent, Span80 and Tween 80 were purchased from Sigma-Aldrich (St. Louis, MO, USA). Cocoa butter and whey protein concentrate $(80 \%$ in protein) were kind donations from Cocoowa (Thessaloniki, Greece) and Tyrokomiki Karditsas S.A. (Karditsa, Greece) respectively. Soybean oil and coconut oil, cocoa powder and sugar were purchased from a local store. Plant material was collected from Moringa oleifera trees grown in the Agioi Apostoloi area of Karditsa prefecture and the moringa leaf extract (MLE) was prepared according to the optimum conditions (ultrasonic pretreatment $30 \mathrm{~min} / 23^{\circ} \mathrm{C}, 100 \mathrm{ml}$ of $75 \% \mathrm{w} / \mathrm{w}$ DES aqueous solution/g of dry plant powder, $200 \mathrm{RPM}$ stirrer speed $/ 150 \mathrm{~min} / 50^{\circ} \mathrm{C}$ ) as established in Lakka et al. (2020). A detailed analysis on the polyphenolic profile of the extract by HPLC means is also given in the same study.

\section{Methods}

\subsection{Microemulsion preparation}

In this study a low energy method was used to prepare $\mathrm{W} / \mathrm{O}$ microemulsions containing Moringa leaf extract with modifications (Yew and Misran, 2015). Initially, the surfactants Span80 and Tween80 (1:1 ratio) and selected oil (soybean or coconut oil) were mixed with a magnetic stirrer for $30 \mathrm{~min}$ at $600 \mathrm{rpm}$. Subsequently, the mixing speed was raised to $1000 \mathrm{rpm}$ and the MLE extract was added dropwise within $40 \mathrm{~min}$. The mixture was left to equilibrate until a homogenous clear microemulsion was formed. Microemulsions containing 4 and $8 \% \mathrm{w} / \mathrm{w}$ MLE and respective blanks containing deep eutectic solvent aqueous solution were prepared as presented in Table 1.

\subsection{Preparation of chocolate bars with microencapsulated MLE}

Chocolate bars were prepared by mixing melted cocoa butter and dry ingredients (whey protein isolate, cocoa powder, sugar) in a lab-scale chocolate melanger (Chocogrind, Elgi Ultra, India). The main methodology for chocolate manufacture involves four distinctive stages: dry mixing, grinding/ refining, conching and moulding (Becket, 2009). Briefly in this study, all dry ingredients $(32 \% \mathrm{w} / \mathrm{w}$ sugar, $12 \%$ cocoa powder and $20 \% \mathrm{w} / \mathrm{w}$ whey protein concentrate) were initially ground in a ball mill for $1 \mathrm{~h}$, melted cocoa butter $(36 \% \mathrm{w} / \mathrm{w})$ was added and the mixture was conched for $2 \mathrm{~h}$ at $70^{\circ} \mathrm{C}$. Chocolate masses were then cooled to $27^{\circ} \mathrm{C}$ and allowed for tempering. Microemulsions containing MLE were incorporated at the end of the tempering phase to prevent the loss of antioxidants. Finally, the temperature was raised to $32{ }^{\circ} \mathrm{C}$, chocolate was poured in high-density polyethylene molds and placed in a cool environment for $24 \mathrm{~h}$ before de-molding. The finished product was sealed in aluminum foil and kept at ambient conditions 
Table 1. Percentage formulation $(\% \mathrm{w} / \mathrm{w})$ of coconut and soybean oil microemulsions.

\begin{tabular}{llll}
\hline Microemulsion formulation & $\begin{array}{l}\text { Surfactant mix } \\
\text { (Tween80+Span80, (1:1)) }\end{array}$ & $\begin{array}{l}\text { Oil phase } \\
\text { (coconut or soybean oil) }\end{array}$ & \begin{tabular}{c} 
Dispersed (DES) phase \\
\hline$\%$ control*
\end{tabular} \\
$4 \%$ MLE & 40 & 56 & 4 \\
$8 \%$ control* & 40 & 56 & 4 \\
$8 \%$ MLE & 40 & 52 & 8 \\
\hline
\end{tabular}

*For control microemulsions the dispersed phase was the DES solution used for MLE preparation.

Table 2. Composition and coding of chocolate samples containing different concentrations of MLE microemulsions.

\begin{tabular}{lll}
\hline Chocolate formulation & Type of microemulsion added in chocolate & Concentration of microemulsion added in chocolate (\% w/w) \\
\hline Control & No added microemulsion & No added microemulsion \\
F4-2 & with 4\% w/w MLE & 2 \\
F4-4 & with $4 \%$ w/w MLE & 2 \\
F8-2 & with $8 \%$ w/w MLE & 4 \\
F8-4 & with $8 \%$ w/w MLE & 4 \\
\hline
\end{tabular}

until further analysis. In total, 5 different formulations were produced with different concentrations of coconut microemulsions containing 4 or $8 \% \mathrm{w} / \mathrm{w}$ MLE. For example, chocolates prepared with $4 \% \mathrm{w} / \mathrm{w}$ MLE microemulsion at $2 \% \mathrm{w} / \mathrm{w}$ concentration are referred as samples F4-2, whereas when the same microemulsion is added at $4 \% \mathrm{w} / \mathrm{w}$ concentration, it is referred as F4-4. Control chocolate bars prepared without microencapsulated MLE served as a reference. Sample codes according to microemulsion formulation and concentration used are summarized in Table 2.

\subsection{Microemulsion droplet size}

The particle size of the microemulsions was estimated by means of dynamic light scattering (DLS) method (Zetasizer NanoZs, Malvern Instruments Ltd., Malvern, Worcestershire, $\mathrm{UK}$ ) equipped with a He-Ne laser beam with a wavelength of $632.8 \mathrm{~nm}$. Measurements were carried out at $90^{\circ}$ scattering angle at $25^{\circ} \mathrm{C}$. Results are expressed as z-average diameter $(\mathrm{nm})$.

\subsection{Radical scavenging activity determination}

The antioxidant activity of the microemulsions and chocolate samples was determined by the scavenging of DPPH.

To determine the antioxidant activity of microemulsions a pretreatment methodology was performed. $0.5 \mathrm{ml}$ of sample was diluted 1:1 with methanol in a $1.5 \mathrm{ml}$ Eppendorf tube and thoroughly mixed with a vortex mixer. Following this, the tubes were centrifuged at $9164 \mathrm{RCF}(=10000 \mathrm{RPM}) / 10 \mathrm{~min} /$ $20{ }^{\circ} \mathrm{C}$ (Ortoalresa Digicen 20-R, Los Frailes, Spain) and supernatants were collected (Poomanee et al., 2017).

In the case of chocolate bars, a pretreatment methodology was followed with modifications (Gültekin-Özgüven et al., 2016). Chocolate samples (1 g) were ground and mixed with
$40 \mathrm{ml}$ of $80 \% \mathrm{w} / \mathrm{v}$ ethanol aqueous solution and sonicated in a water bath $\left(40^{\circ} \mathrm{C} / 25 \mathrm{~min}\right)$. Finally, the samples were centrifuged as in the case of the microemulsions and the supernatants were collected.

The radical scavenging activity of microemulsion and chocolate supernatants was estimated according to Lakka et al. (2020). In brief, $25 \mu \mathrm{l}$ of each supernatant was mixed with $975 \mu$ l of DPPH solution ( $100 \mu \mathrm{M}$ in methanol) and left in the dark for $30 \mathrm{~min}$. Then the absorbance was measured at $515 \mathrm{~nm}$ (Shimadzu UV-1700). Results were expressed as percentage of Inhibition ( $\mathrm{I} \%$ ) against blank according to equation (1):

$$
(\mathrm{I} \%)=100 \times\left(\mathrm{A}_{0}-\mathrm{A}_{\mathrm{s}}\right) \div \mathrm{A}_{0},
$$

where, $\mathrm{A}_{0}$ and $\mathrm{A}_{\mathrm{s}}$ are the absorbance at $515 \mathrm{~nm}$ of the blank and the sample respectively (Poomanee et al., 2017).

\subsection{Thermal stability of microemulsions}

To determine the stability of the microemulsions against high temperatures $2 \mathrm{ml}$ of each sample was placed in glass tubes and placed in thermostated water baths at 50,60 and $70{ }^{\circ} \mathrm{C}$ for $1 \mathrm{~h}$. At the end of the thermal treatment the stability of the samples was checked visually for phase separation.

\subsection{Accelerated stability test of microemulsions}

Microemulsion samples were centrifuged at $3000 \mathrm{rpm}$ for $20 \mathrm{~min}\left(25^{\circ} \mathrm{C}\right)$ (Ortoalresa Digicen $20-\mathrm{R}$, Los Frailes, Spain) and visually examined for phase separation (Rashid et al., 2019).

\subsection{Color measurement}

Color properties of the chocolate samples were estimated by a color and appearance measurement system (Lovibond 
Table 3. Average particle size (z-average diameter) of microemulsions prepared with coconut and soybean oil.

\begin{tabular}{|c|c|}
\hline Microemulsion formulation & $\mathrm{z}$-average diameter $(\mathrm{nm})$ \\
\hline \multicolumn{2}{|l|}{ Coconut oil microemulsions } \\
\hline $4 \%$ Control & $15.1^{\mathrm{a}} \pm 2.2$ \\
\hline 4\% MLE & $28.3^{\mathrm{bc}} \pm 5.4$ \\
\hline $8 \%$ Control & $29.2^{\mathrm{bc}} \pm 7.3$ \\
\hline $8 \%$ MLE & $63.8^{\mathrm{e}} \pm 12.0$ \\
\hline \multicolumn{2}{|l|}{ Soybean oil microemulsions } \\
\hline $4 \%$ Control & $23.3^{\mathrm{b}} \pm 1.2$ \\
\hline 4\% MLE & $32.8^{\mathrm{c}} \pm 1.4$ \\
\hline $8 \%$ Control & $40.1^{\mathrm{d}} \pm 3.3$ \\
\hline $8 \%$ MLE & $82.6 \pm 4.6$ \\
\hline
\end{tabular}

CAM-System 500, Great Britain). The system was calibrated using the Gretamacbeth mini color checker model P/N:50111, to obtain $\mathrm{L}^{*}, \mathrm{a}^{*}, \mathrm{~b}^{*}$ CIE values. The Whiteness Index (WI) was also calculated according to equation (2) as follows (Briones and Aguilera, 2005):

$$
\mathrm{WI}=100-\left[\left(100-\mathrm{L}^{*}\right)^{2}+\left(\mathrm{a}^{*}\right)^{2}+\left(\mathrm{b}^{*}\right)^{2}\right]^{0.5} .
$$

\subsection{Statistical analysis}

All physicochemical analyses were performed in triplicate. The statistical analysis was performed with StatGraphics Centurion XV software by means of analysis of variance (ANOVA) at 95\% level of confidence $(p<0.05)$.

\section{Results and discussion}

\subsection{Microemulsion size}

In Table 3, the z-average diameter of the blank and MLE microemulsions is presented.

The average diameter of microemulsion droplet ranged from 15.1 to $82 \mathrm{~nm}$, typical of microemulsion formation. Typically, droplet sizes below $100 \mathrm{~nm}$ ensure the clear transparent/translucent appearance of microemulsions (McClements, 2012). The increase of dispersed phase (DES aqueous solution or MLE) from 4 to $8 \% \mathrm{w} / \mathrm{w}$ resulted in larger droplet formation (Lou et al., 2013). The type of oil phase used had also a profound effect on particle size. Coconut oil microemulsions are characterized by finer droplet compared to soybean oil samples $(p<0.05)$. Coconut oil has been used successfully to fabricate microemulsions with similar formulation of low molecular weight emulsifiers (Rukmini et al., 2012; Ja'afar et al., 2019). It contains high amounts of medium chain triglycerides (MCTs) including lauric, myristic and caprylic acid (Pengon et al., 2018). On the other hand, soybean oil is mainly composed of long chain triaglycerols (LCTs) that are less soluble in microemulsions due to long chain fatty acids which are bulky enough and unable to reach the interfacial film (Flanagan et al., 2006). Similarly, in a comparative study for microemulsions formed with vegetable oils (coconut, palm kernel and soybean oil) larger droplet sizes are reported for LCT oils (Lee et al., 2017).

\subsection{Stability evaluation}

In Figures 1 and 2, the stability of coconut and soybean oil microemulsions after centrifugation and thermal treatment is depicted. Microemulsion stability can be affected by various environmental conditions including $\mathrm{pH}$, ionic strength, centrifugation and temperature ( $\mathrm{Li}$ et al., 2017; Cortés et al., 2019). Moderate temperatures can favor microemulsion formation by altering the solubility of surfactants (Li et al., 2017) resulting in lower interfacial tension. However, high temperatures promote inter-droplet interactions leading to droplet aggregation, subsequent coalescence and finally phase separation (Shi et al., 2015). Centrifugation tests are considered as an effective way to evaluate microemulsion stability because they show good correlation with traditional gravitational stability testing, which is more time consuming as it requires prolonged periods of evaluation, often of several months (Mouri et al., 2016). In the case of W/O microemulsions, destabilization is recognized by the sedimentation of aqueous phase at the bottom (Poomanee et al., 2017). As seen in Figure 1, all microemulsion formulations were stable against centrifugation regardless of the oil phase used (soybean or coconut oil) and percentage of added moringa leaf extract, as they appeared transparent even after strong agitation. Microemulsion stability remained also unaffected by thermal treatment at 50,60 or $70^{\circ} \mathrm{C} / 1 \mathrm{~h}$ as demonstrated in Figure 2 . Researchers who studied the stability of coconut $\mathrm{W} / \mathrm{O}$ microemulsions at elevated temperatures found that formulations were unstable at $70^{\circ} \mathrm{C}$, although samples were kept at that temperature for longer time intervals $(5 \mathrm{~h})$ (Rukmini et al., 2012). Similarly, o/w microemulsions were subjected to a high temperature treatment $\left(105^{\circ} \mathrm{C}\right)$ for several days for destabilization to occur (Cho et al., 2008).

\subsection{Antioxidant activity of microemulsions}

The DPPH radical scavenging activity of microemulsions prepared with different types of oil phase is shown in Figure 3. Percentage inhibition (I\%) values for soybean oil microemulsions ranged between $\sim 23$ to $28.6 \%$, significantly higher than those of microemulsions prepared with coconut oil (11.6$15.8 \%)(p<0.05)$. Comparative studies regarding the antioxidant activity of vegetable oils have shown that soybean oil demonstrates superior radical scavenging properties than coconut oil (Bhatnagar et al., 2009; Goldson et al., 2018). Indeed, it is reported that soybean oil is rich in tocopherols which account for $990-1670 \mathrm{mg} / \mathrm{kg}$, whereas for coconut oil a concentration as low as $17-29 \mathrm{mg} / \mathrm{kg}$ is noticed (Hildebrand et al., 1984; Jung et al., 1989; Bhatnagar et al., 2009; Raja et al., 2010). On the contrary, higher phenolic contents up to $29 \mathrm{mg} / 100 \mathrm{~g}$ have been reported for coconut oil depending on processing (Marina et al., 2009), whereas soybean oil contains phenolic compounds in small quantities $(1.4 \mathrm{mg} / 100 \mathrm{~g}$ oil) (Siger et al., 2008).

Consequently, the increase of MLE concentration from 4 to $8 \% \mathrm{w} / \mathrm{w}$ did not significantly increase the inhibition values 


\section{Coconut oil microemulsions}

Before centrifugation

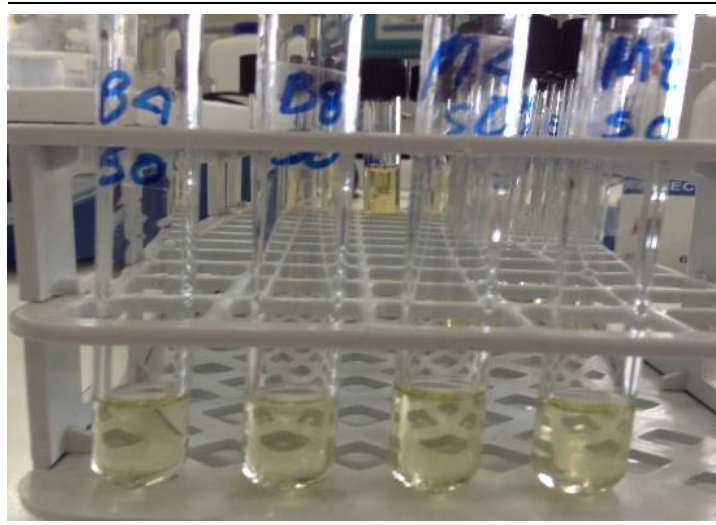

Control 4\% Control 8\%

MLE 4\% MLE 8\%

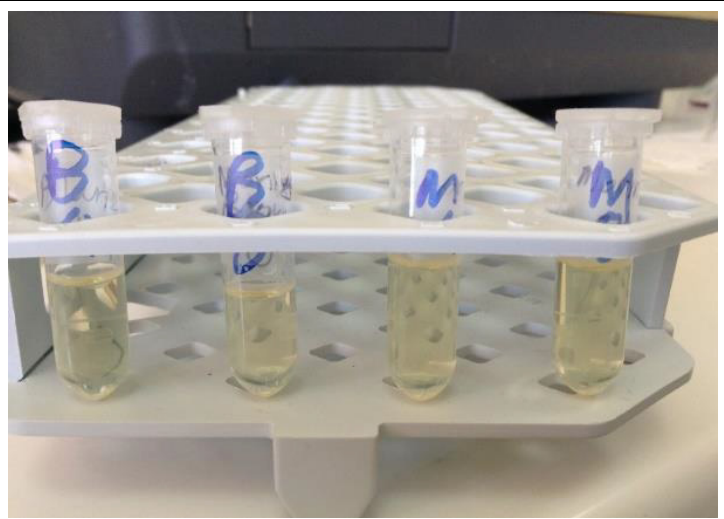

Control 4\% Control 8\% MLE 4\% MLE 8\%

\section{Soybean oil microemulsions}

Before centrifugation

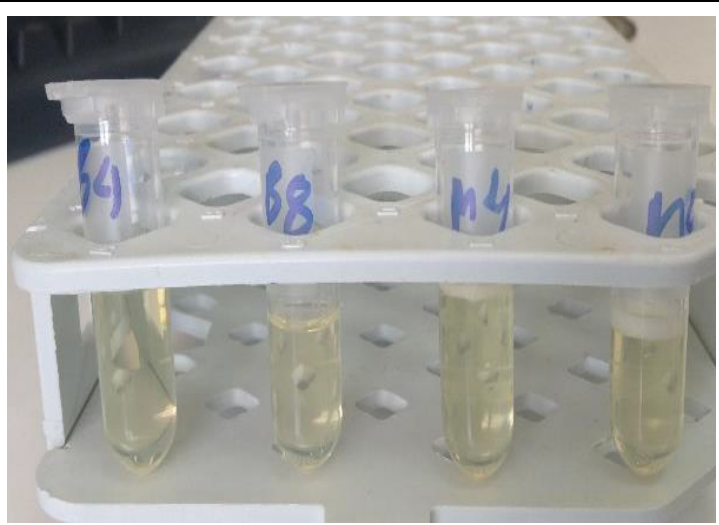

Control 4\% Control 8\% MLE 4\% MLE 8\%
After centrifugation

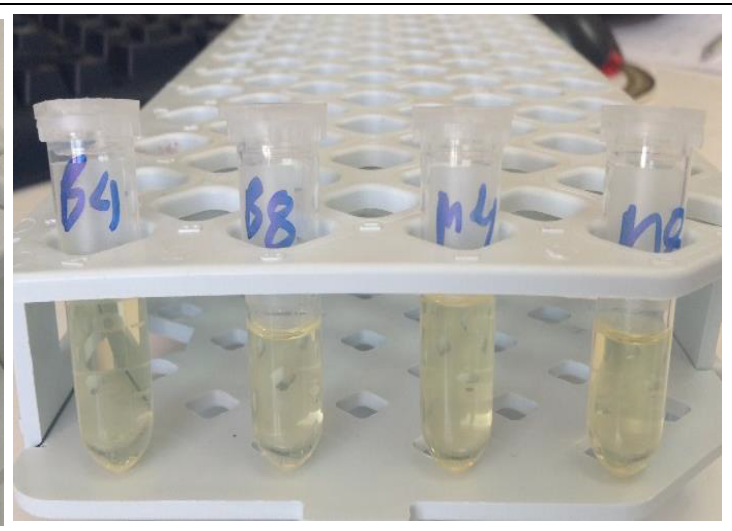

Control 4\% Control 8\% MLE 4\% MLE 8\%

Fig. 1. Microemulsion stability assessed by accelerated centrifugal testing (3000 RPM/20 min) (from left to right: Blank microemulsion $4 \%$, blank $8 \%$, with $4 \%$ MLE and with $8 \%$ MLE).

$(p>0.05)$. In general, the addition of antioxidants is expected to increase the radical scavenging capacity of such systems. For instance, the addition of purple sweet potato extract in W/ O microemulsion formed with olive oil presented 30\% higher DPPH inhibition values compared to the control sample (Desnita et al., 2016). However, the concentration of the purple potato extract used in this case was considerably higher $(\sim 38 \% \mathrm{w} / \mathrm{w})$. Our finding is in accordance with Vorarat et al. (2010) who reported almost equal I\% values for microemulsions containing $20 \%$ rice bran oil and $10 \%$ rice bran oil + oryzanol. This could be due to the subsequent decrease of the oil phase and respective antioxidants contained. Indeed, a positive "quasi-linear" effect of oil concentration on radical inhibition values has also been reported in emulsions formed with plant derived oil (sea buckthorn oil) which has considerable amounts of antioxidants (Zheng et al., 2020).

\subsection{Antioxidant activity and color properties of chocolate products during storage}

In this section, coconut oil microemulsions were incorporated in chocolates since coconut oil is a known substitute for cocoa butter, although restrictions may apply depending on national legislations and this type of products are referred as compound chocolate (Halim et al., 2019). 

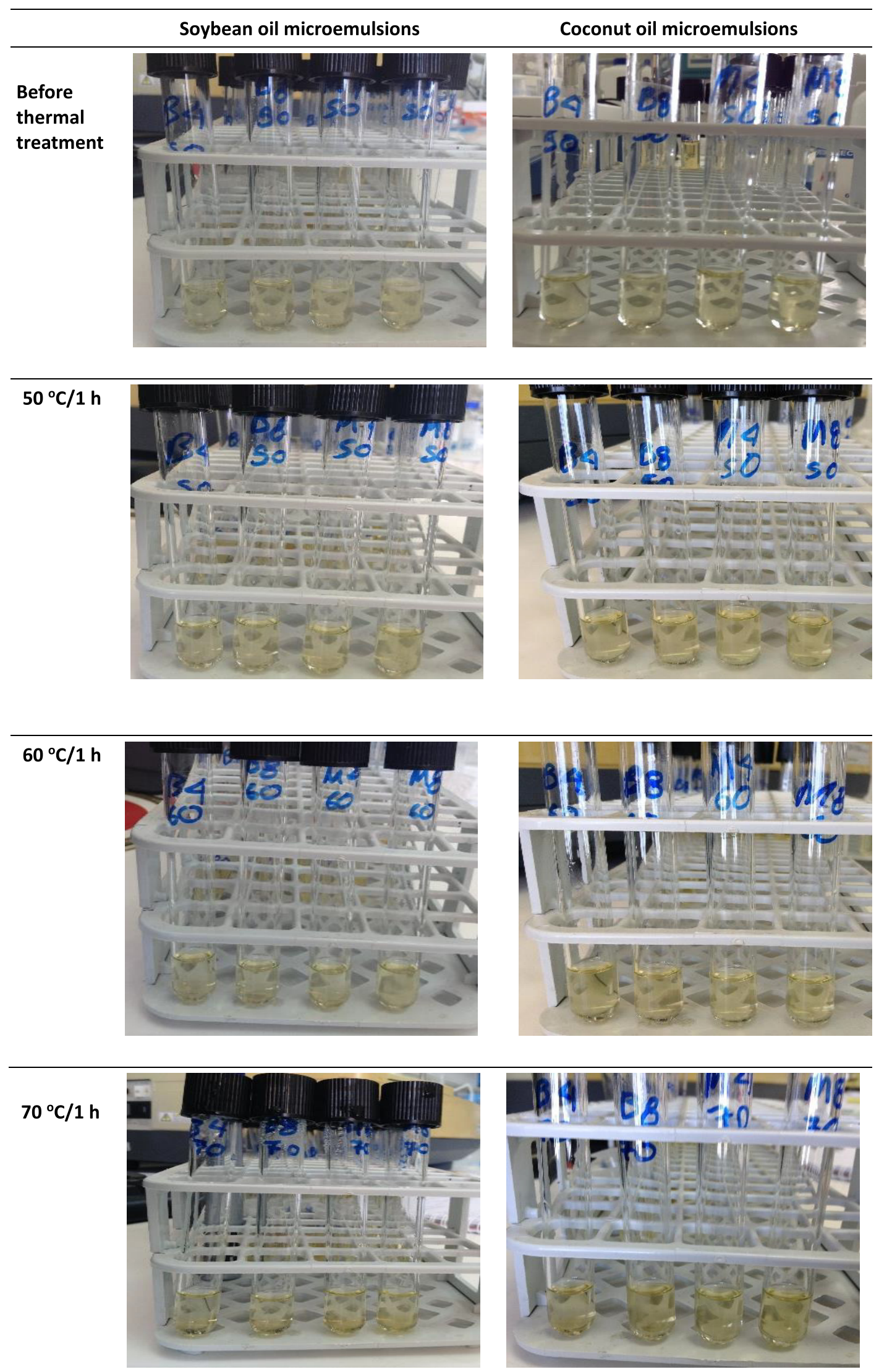

Fig. 2. Stability of microemulsions against thermal treatment $\left(50,60\right.$ and $70{ }^{\circ} \mathrm{C} / 1 \mathrm{~h}$ ) (from left to right: control microemulsion $4 \%$, control $8 \%$, with $4 \%$ MLE and with $8 \%$ MLE). 


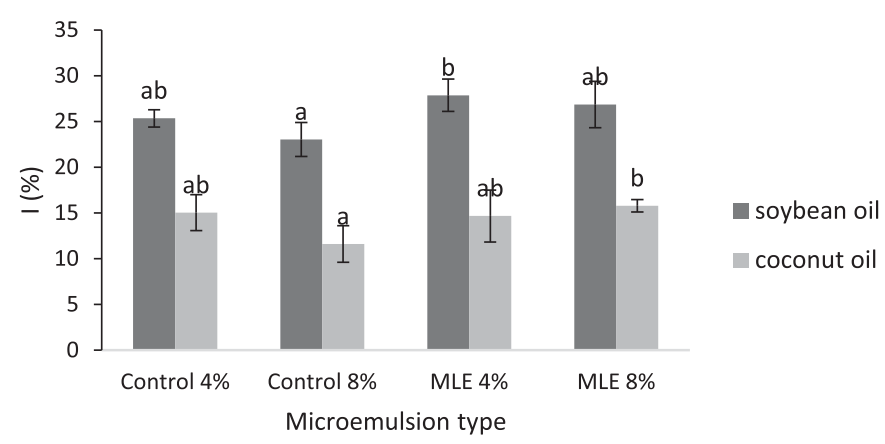

Fig. 3. Antioxidant capacity of microemulsions as affected by oil phase type and MLE concentration.

Different small letters among samples prepared with the same oil indicate statistically significant differences $(p<0.05)$.

Color is considered as a very important property as it can affect consumer behavior and modify other organoleptic characteristics such as taste and/or flavor of food (Williams, 1992; Spence and Piqueras-Fiszman, 2016). The main phenomenon governing the appearance of chocolate during storage is blooming. Blooming is the migration of fat to the surface of chocolate caused by exposure to high ambient temperatures leading to loss of gloss, irregular whitish flaky pattern formation and color degradation (Briones and Aguilera, 2005).

Figure 4 shows the evolution of color properties $\left(\mathrm{L}^{*}, \mathrm{a}^{*}\right.$, $\mathrm{b}^{*}$ ) and whiteness (WI) of chocolate samples containing MLE coconut oil microemulsions during 8 months of storage. The WI is a useful colorimetric parameter that can be used to monitor the migration of fat on the surface of chocolate accumulated in white spots (Mexis et al., 2010). It can be seen that chocolate formulation had a minor effect on color properties of fresh samples. With the exception of sample 84 that contained the highest amount of MLE microemulsion, all other samples presented similar values of $L^{*}, a^{*}, b^{*}$ and WI. Storage on the other hand affected majorly all color parameters. Sample lightness $\left(\mathrm{L}^{*}\right)$ of freshly prepared chocolates ranged between 37.9 and 41.8 and gradually increased to levels of 50-60. The same trend was also observed for WI values, which were increased by a factor of 1.36 on average. It should be mentioned though that reference chocolates that did not contain microencapsulated MLE presented the lowest WI values, hence they were the least ones affected by blooming during storage, whereas slightly higher values were observed for enriched chocolates. Several studies have shown that coconut oil - that is the main ingredient of MLE microemulsions incorporated in chocolates - exhibits anti-blooming properties when added in chocolate even at levels as low as $\sim 4.5 \%$ (Putri Limbardo et al., 2017; Halim et al., 2019). However, in this study the amount of coconut oil incorporated in chocolate in the form of microemulsion is much lower, which could possibly justify the absence of the antiblooming effect. Finally, the amount of microemulsion and MLE added did not affect the blooming of the chocolate samples. All samples containing microencapsulated MLE presented similar WI values $(p>0.05)$ after 8 months of storage.
The antioxidant activity of chocolates is demonstrated in DPPH inhibition (I\%) (Fig. 5). Freshly prepared chocolate samples presented similar I\% values ranging between 12.8 $14.7 \%(p>0.05)$. The fact that MLE enriched chocolates did not exhibit superior antioxidant activity compared to control chocolate could be due to the high content of chocolates in phenolic compounds derived from cocoa nib derivatives. For example, researchers have reported total phenolic contents between 47.17-57.16 and 39.1-39.9 mgGAE/g of chocolate accordingly (Batista et al., 2016; Di Mattia et al., 2017). However, MLE used in this study contains $\sim 94 \mathrm{mgGAE} / \mathrm{g}$ (Lakka et al., 2020) and is only added at a maximum $8 \% \mathrm{w} / \mathrm{w}$ in the microemulsions.

A small loss of antioxidant activity by $2.5 \%$ on average was also observed in all samples after 8 months of storage, as seen by DPPH inhibition values that decreased to $11.1-11.6 \%$ levels. This finding is in accordance with other similar studies regarding the effect of storage on the antioxidant capacity of chocolate products (Pavlovic et al., 2017) and is related to the degradation of major polyphenol compounds (flaval-3-ols, anthocyanins, catechins, procyanidins and proanthocyanidins) (Laličić-Petronijević et al., 2016; Pavlovic et al., 2017; Roda and Lambri, 2019).

\section{Conclusions}

Moringa oleifera leaf extract (MLE) was successfully encapsulated in microemulsions prepared with different plant oils. The antioxidant activity of microemulsions depends on oil type used, with soybean oil demonstrating superior radical scavenging properties. Even though enrichment of chocolate products with MLE in the form of microemulsions did not affect the color properties and overall acceptance of products, nevertheless its application in chocolate products is limited due to poor beneficial antioxidant effect observed following incorporation.

\section{Funding}

This research has been co-financed by the European Union and Greek national funds through the Operational Program Competitiveness, Entrepreneurship and Innovation, under the call RESEARCH-CREATE-INNOVATE (project code: T1EDK-05677).

\section{Author contributions}

S.I.L., D.P.M., experimental design, funding acquisition, supervision, monitoring of research work, manuscript, reviewing; O.K. experimental design, laboratory work, analysis, writing, statistical analysis; A.A., G.B., E.B., laboratory work, analysis; All authors have read and agreed to the published version of the manuscript.

Conflicts of interest. The authors declare no conflicts of interest. 

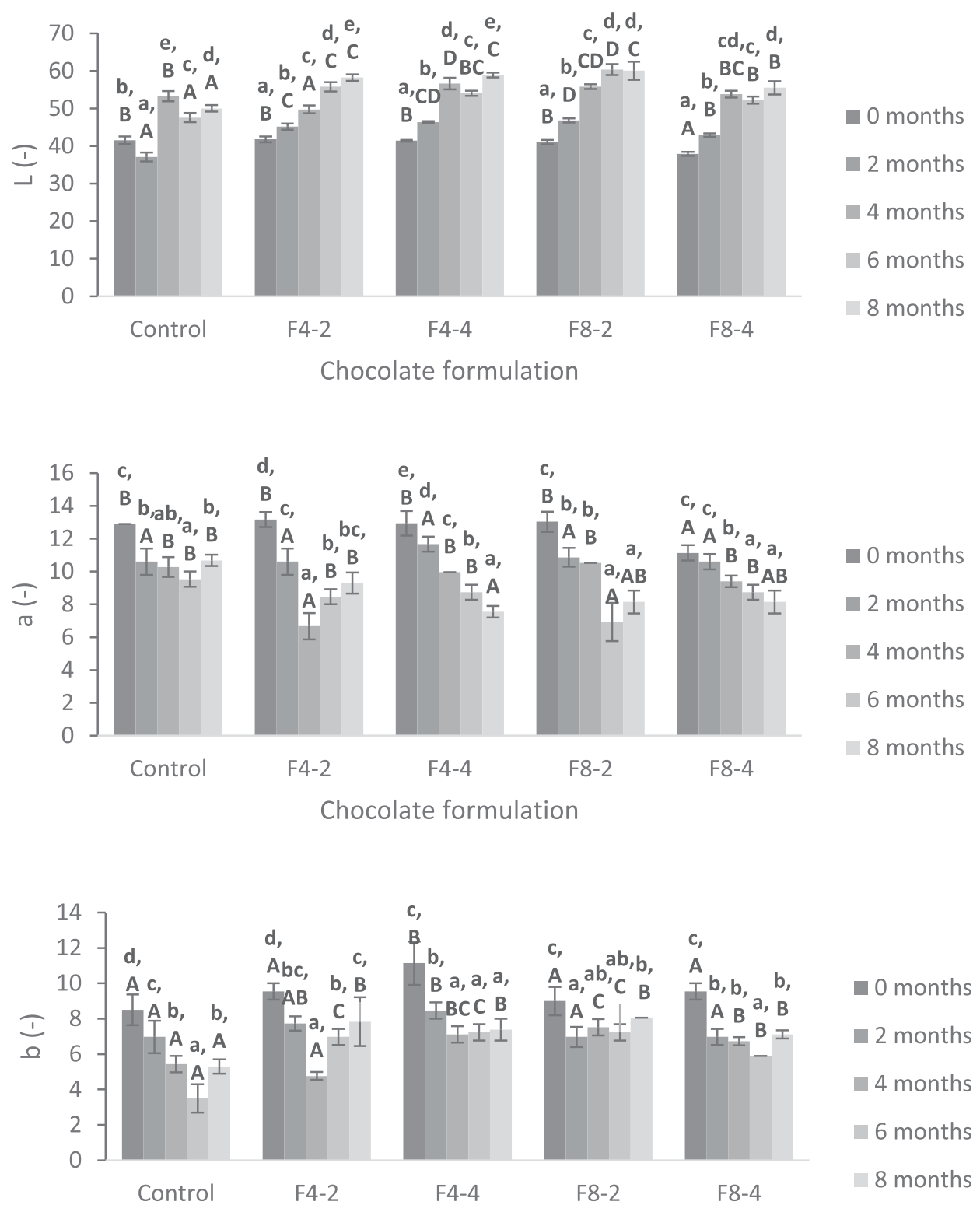

Chocolate formulation

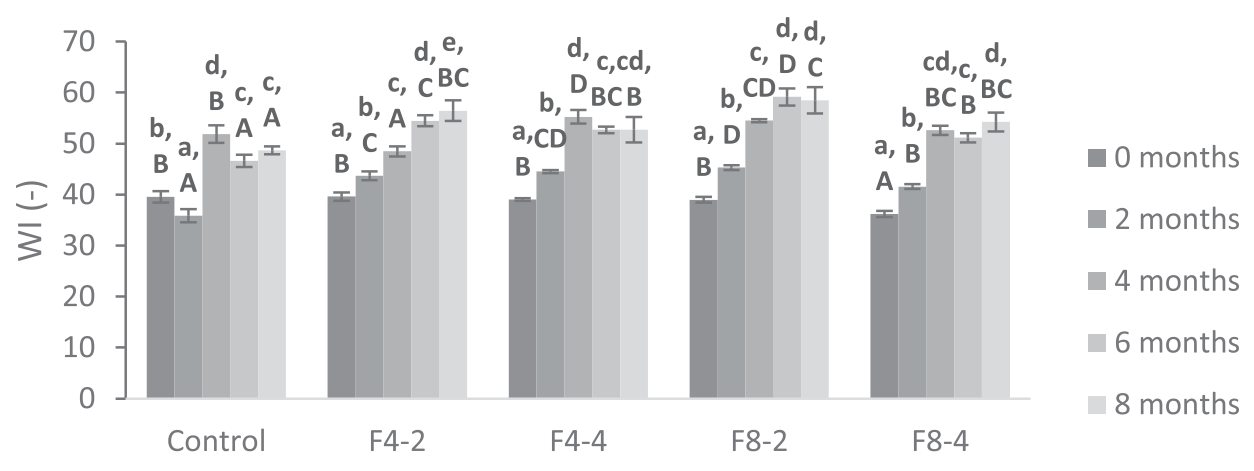

Chocolate formulation

Fig. 4. Color properties of chocolate products as affected by composition and storage.

Different small letters for the same sample indicate statistically significant differences during storage $(p<0.05)$.

Different capital letters among samples of the same storage indicate statistically significant differences $(p<0.05)$. 


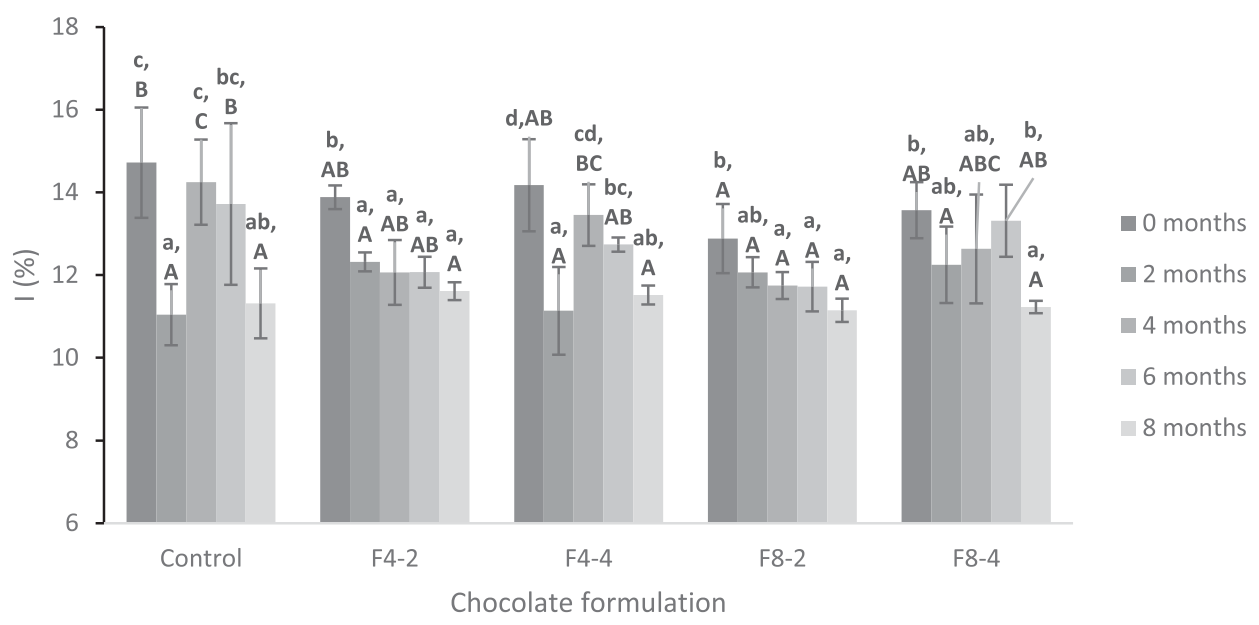

Fig. 5. Antioxidant capacity of chocolate products as affected by composition and storage.

Different small letters for the same sample indicate statistically significant differences during storage $(p<0.05)$.

Different capital letters among samples of the same storage indicate statistically significant differences $(p<0.05)$.

\section{References}

Akhtar S, Anjum FM, Anjum MA. 2011. Micronutrient fortification of wheat flour: Recent development and strategies. Food Res Int 44: 652-659. https://doi.org/10.1016/j.foodres.2010.12.033.

Batista NN, Pereira de Andrade D, Lacerda Ramos C, Ribeiro Dias D, Freitas Schwan R. 2016. Antioxidant capacity of cocoa beans and chocolate assessed by FTIR. Food Res Int 90: 313-319. https:// doi.org/10.1016/j.foodres.2016.10.028.

Batra G, Gortzi O, Lalas SI, Galidi A, Alibade A, Nanos GD. 2017. Enhanced antioxidant activity of Capsicum annuum L. and Moringa oleifera L. extracts after encapsulation in microemulsions. Chem Eng 1: 15. https://doi.org/10.3390/chemengin eering 1020015.

Becket ST. 2009. Industrial chocolate manufacture and use, 4th ed. New Jersey (USA): Blackwell Publishing Ltd, pp. 192-357. https://doi.org/10.1111/j.1365-2621.2009.02041.x.

Bhatnagar AS, Prasanth Kumar PK, Hemavathy J, Gopala-Krishna AG. 2009. Fatty acid composition, oxidative stability, and radical scavenging activity of vegetable oil blends with coconut oil. $\mathrm{J} \mathrm{Am}$ Oil Chem Soc 86: 991-999.

Briones V, Aguilera JM. 2005. Image analysis of changes in surface color of chocolate. Food Res Int 38: 87-94.

Castro Coelho S, Nogueiro Estevinho B, Rocha F. 2021. Encapsulation in food industry with emerging electrohydrodynamic techniques: Electrospinning and electrospraying - A review. Food Chem 339: 127850. https://doi.org/10.1016/j.food chem.2020.127850.

Cho YH, Kim S, Bae E, Mok C, Park J. 2008. Formulation of a cosurfactant-free $\mathrm{O} / \mathrm{W}$ microemulsion using nonionic surfactant mixtures. J Food Sci 73: 115-121. https://doi.org/10.1111/ j.1750-3841.2008.00688.x.

Cortés NM, Califano AN, Lorenzo G. 2019. Physical and chemical stability under environmental stress of microemulsions formulated with fish oil. Food Res Int 119: 283-290. https://doi.org/ 10.1016/j.foodres.2019.01.067.

Desnita R, Veronika M, Wahdaningsih S. 2016. Topical microemulsion's formulation of purple sweet potato (Ipomoea batatas L.) ethanol extract as antioxidant by using various concentration of Span80. Int J Pharm Tech Res 9(3): 234-239.
Dhakad AK, Ikram M, Sharma S, Khan S, Pandey VV, Singh A. 2019. Biological, nutritional, and therapeutic significance of Moringa oleifera Lam. Phytother Res 33: 2870-2903. https://doi.org/ 10.1002/ptr.6475.

Di Mattia C, Giampiero S, Mastrocola D, Serafini M. 2017. From cocoa to chocolate: the impact of processing on in vitro antioxidant activity and the effects of chocolate on antioxidant markers in vivo. Front Immunol 8: 1207. https://dx.doi.org/ 10.3389\%2Ffimmu.2017.01207.

Flanagan J, Singh H. 2006. Microemulsions: A potential delivery system for bioactives in food. Crit Rev Food Sci Nutr 46: 221237. https://doi.org/10.1080/10408690590956710.

Flanagan J, Kortegaard K, Neil Pinder D, Rades T, Singh H. 2006. Solubilisation of soybean oil in microemulsions using various surfactants. Food Hydrocoll 20: 253-260. https://doi.org/ 10.1016/j.foodhyd.2005.02.017.

Goldson Barnaby A, Clarke J, Warren D, Duffus K. 2018. Free radical scavenging capacity, carotenoid content, and NMR characterization of Blighia sapida aril oil. J Lipids 2018: 1-7. https://dx.doi. org/10.1155\%2F2018\%2F1762342.

Gültekin-Özgüven M, Berktas İ, Özçelik B. 2016. Influence of processing conditions on procyanidin profiles and antioxidant capacity of chocolates: Optimization of dark chocolate manufacturing by response surface methodology. LWT 66: 252-59. https://doi.org/10.1016/j.lwt.2015.10.047.

Halim HSA, Selamat J, Mirhosseini SH, Hussain N. 2019. Sensory preference and bloom stability of chocolate containing cocoa butter substitute from coconut oil. J Saudi Soc Agric Sci 18: 443 448. https://doi.org/10.1016/j.jssas.2018.02.005.

Hildebrand DH, Terao J, Kito M. 1984. Phospholipids plus tocopherols increase soybean oil stability. J Am Oil Chem Soc 61: 552-555. https://doi.org/10.1016/j.jssas.2018.02.005.

Ja'afar SM, Khalid RM, Othaman R, Mokhtar WNAW, Ramli S. 2019. Coconut oil based microemulsion formulations for hair care product application. Sains Malays 48: 599-605. http://dx.doi.org/ 10.17576/jsm-2019-4803-12.

Jalali-Jivan M, Garavand F, Jafari SM. 2020. Microemulsions as nano-reactors for the solubilization, separation, purification and encapsulation of bioactive compounds. Adv Colloid Interface Sci 283: 102227. https://doi.org/10.1016/j.cis.2020.102227. 
Jung MY, Yoon SH, Min DB. 1989. Effects of processing steps on the contents of minor compounds and oxidation of soybean oil. $\mathrm{J} \mathrm{Am}$ Oil Chem Soc 66: 118-120. https://doi.org/10.1007/BF02661798.

Karageorgou I, Grigorakis S, Lalas S, Makris DP. 2017. Enhanced extraction of antioxidant polyphenols from Moringa oleifera Lam. leaves using a biomolecule-based low-transition temperature mixture. Eur Food Res Technol 243: 1839-1848. https://doi. org/10.1007/s00217-017-2887-1.

Lakka A, Grigorakis S, Kaltsa O, et al. 2020. The effect of ultrasonication pretreatment on the production of polyphenolenriched extracts from Moringa oleifera L. (drumstick tree) using a novel bio-based deep eutectic solvent. Appl Sci 10: 220. https:// doi.org/10.3390/app10010220.

Lalas S, Tsaknis J. 2002. Extraction and identification of natural antioxidant from the seeds of the Moringa oleifera tree variety of Malawi. J Am Oil Chem Soc 79: 792-99. https://doi.org/10.1007/ s11746-002-0542-2.

Laličić-Petronijević J, Komes D, Gorjanović S, et al. 2016. Content of total phenolics, flavan-3-ols and proanthocyanidins, oxidative stability and antioxidant capacity of chocolate during storage. Food Technol Biotechnol 54: 13-20. https://dx.doi.org/ $10.17113 \% 2 \mathrm{Fftb} .54 .01 .16 .4014$.

Lee SY, Ng A, Jaswan Singh MS, Liew YK, Gan SN, Koh RY. 2017. Physicochemical and antimicrobial properties of natural rubber latex films in the presence of vegetable oil microemulsions. $J \mathrm{Appl}$ Polym Sci 134: 44788-44795. https://doi.org/10.1002/app.44788.

Li Y, Yokoyama W, Xu S, Zhu S, Ma J, Zhong F. 2017. Formation and stability of W/O microemulsion formed by food grade ingredients and its oral delivery of insulin in mice. J Funct Foods 30: 134141. https://doi.org/10.1111/j.1750-3841.2008.00688.x.

Lin M, Zhang J, Chen X. 2018. Bioactive flavonoids in Moringa oleifera and their health-promoting properties. J Funct Foods 47: 469-479. https://doi.org/10.1016/j.jff.2018.06.011.

Lou H, Qiu N, Crill C, Helms R, Almoazen H. 2013. Development of W/O microemulsion for transdermal delivery of iodide ions. AAPS Pharm Sci Tech 14: 168-176. https://dx.doi.org/10.1208\% 2Fs12249-012-9901-5.

Marina AM, Che Man YB, Nazimah SAH, Amin I. 2009. Chemical properties of virgin coconut oil. J Am Oil Chem Soc 86: 301-307. https://doi.org/10.1007/s11746-009-1351-1.

Maurya VK, Bashir K, Aggarwal M. 2020. Vitamin D microencapsulation and fortification: Trends and technologies. J Steroid Biochem Mol Biol 196: 105489. https://doi.org/10.1016/j. jsbmb.2019.105489.

McClements DJ. 2012. Nanoemulsions versus microemulsions: Terminology, differences, and similarities. Soft Matter 8: 1719-1729. https://doi.org/10.1039/C2SM06903B.

McClements DJ. 2018. Recent developments in encapsulation and release of functional food ingredients: delivery by design. Curr Opin Food Sci 23: 80-84. https://doi.org/10.1016/j. cofs.2018.06.008.

Mexis SF, Badeka AV, Riganakos KA, Kontominas MG. 2010. Effect of active and modified atmosphere packaging on quality retention of dark chocolate with hazelnuts. Innov Food Sci Emerg Technol 11: 177-186. https://doi.org/10.1016/j.ifset.2009.09.001.

Moreira A, Lawson D, Onyekuru L, et al. 2020. Protein encapsulation by electrospinning and electrospraying. J Control Release. https:// doi.org/10.1016/j.jconrel.2020.10.046.

Mouri A, Legrand P, El Ghzaoui A, Dorandeu C, Maurel JC, Devoisselle JM. 2016. Formulation, physicochemical characterization and stability study of lithium-loaded microemulsion system. Int $J$ Pharm 502: 117-124. https://doi.org/10.1016/j. ijpharm.2016.01.072.
Pavlovic A, Mrmosanin J, Krstic J, et al. 2017. Effect of storage temperature on the decay of catechins and procyanidins in dark chocolate. Czech J Food Sci 35: 360-366. https://doi.org/ 10.17221/265/2016-CJFS.

Pengon S, Chinatangkul N, Limmatvapirat C, Limmatvapirat S. 2018. The effect of surfactant on the physical properties of coconut oil nanoemulsions. Asian J Pharm 13: 409-414. https://doi.org/ 10.1016/j.ajps.2018.02.005.

Poomanee W, Chaiyana W, Wickett RR, Leelapornpisid P. 2017. Stability and solubility improvement of Sompoi (Acacia concinna Linn.) pod extract by topical microemulsion. Asian J Pharm 12: 386-393. https://doi.org/10.1016/j.ajps.2017.03.001.

Putri Limbardo R, Santoso H, Retti Witono J. 2017. The effect of coconut oil and palm oil as substituted oils to cocoa butter on chocolate bar texture and melting point. In: Proceedings of AIP Conference, Surabaya, Indonesia, May 1st, 2017, 1840(1). https:// doi.org/10.1063/1.4982281.

Raja RG, Prasanth Kumar PK, Gopala Krishna AG. 2010. Tocopherols and Phytosterols content of coconut oil blends prepared for coconut oil consumers and non coconut oil consumers. Indian Coconut J 53: 16-20.

Rashid MA, Naz T, Abbas M, et al. 2019. Chloramphenicol loaded microemulsions: Development, characterization and stability. Coll Interface Sci Commun 28: 41-48. https://doi.org/10.1016/j. colcom.2018.11.006.

Ray S, Raychaudhuri U, Chakraborty R. 2016. An overview of encapsulation of active compounds used in food products by drying technology. Food Biosci 13: 76-83. https://doi.org/ 10.1016/j.fbio.2015.12.009.

Roda A, Lambri M. 2019. Changes in antioxidants and sensory properties of italian chocolates and related ingredients under controlled conditions during an eighteen-month storage period. Nutrients 11: 2719. https://doi.org/10.3390/nu11112719.

Rukmini A, Raharjo S, Hastuti P, Supriyadi S. 2012. Formulation and stability of water-in-virgin coconut oil microemulsion using ternary food grade nonionic surfactants. Int Food Res J 19: 259-264.

Sermkaew N, Plyduang T. 2020. Self-microemulsifying drug delivery systems of Moringa oleifera extract for enhanced dissolution of kaempferol and quercetin. Acta Pharm 70: 77-88. https://doi.org/ 10.2478/acph-2020-0012.

Shi J, Jun Xue S, Wang B, Wang W, Ye X, Quek SW. 2015. Optimization of formulation and influence of environmental stresses on stability of lycopene-microemulsion. LWT 60: 9991008. https://doi.org/10.1590/fst.42017.

Shilpashree BG, Arora S, Sharma, V, Singh AK. 2015. Preparation of succinylated sodium caseinate-iron complex by adopting ultrafiltration technology: A novel food fortificant. Innov Food $S c i$ Emerg Technol 32: 165-171. https://doi.org/10.1016/j. ifset.2015.09.020.

Siger A, Nogala-Kalucka M, Lampart-Szczapa E. 2008. The content and antioxidant activity of phenolic compounds in cold-pressed plant oils. J Food Lipids 15: 137-149. https://doi.org/10.1111/ j.1745-4522.2007.00107.x.

Soliman MM, Aldhahrani A, Alkhedaide A, Nassan MA, Althobaiti F, Mohamed WA. 2020. The ameliorative impacts of Moringa oleifera leaf extract against oxidative stress and methotrexateinduced hepato-renal dysfunction. Biomed Pharmacother 128: 110259. https://doi.org/10.1016/j.biopha.2020.110259.

Spence C, Piqueras-Fiszman B. 2016. Food color and its impact on taste/flavor perception. In: Spence C, Piqueras-Fiszman B, eds. Multisensory flavor perception: From fundamental neuroscience 
through to the marketplace, 1st ed. Amsterdam (The Netherlands): Elsevier Inc. Academic Press, pp. 107-132.

Suresh S, Chhipa AS, Gupta M, et al. 2020. Phytochemical analysis and pharmacological evaluation of methanolic leaf extract of Moringa oleifera Lam. in ovalbumin induced allergic asthma. $S$ Afr J Bot 130: 484-493. https://doi.org/10.1016/j. sajb.2020.01.046.

Syeda AM, Riazunnisa K. 2020. Data on GC-MS analysis, in vitro antioxidant and anti-microbial activity of the Catharanthus roseus and Moringa oleifera leaf extracts. Data Brief 29: 105258. https:// doi.org/10.1016/j.dib.2020.105258.

Vorarat S, Managit C, Iamthanakul L, Soparat W, Kamkaen N. 2010. Examination of antioxidant activity and development of rice bran oil and gamma-oryzanol microemulsion. J Health Res 24(2): $67-72$.

Wang F, Long S, Zhang J, et al. 2020. Antioxidant activities and antiproliferative effects of Moringa oleifera $\mathrm{L}$. extracts with head and neck cancer. Food Biosci 37: 100691. https://doi.org/10.1016/j. fbio.2020.100691.
Williams WD. 1992. Origin and impact of color on consumer preference for food. Poult Sci 71: 744-746. https://doi.org/ 10.3382/ps.0710744.

Ye Q, Georges N, Selomulya C. 2018. Microencapsulation of active ingredients in functional foods: From research stage to commercial food products. Trends Food Sci Technol 78: 167179. https://doi.org/10.1016/j.tifs.2018.05.025.

Yew HC, Misran M. 2015. Nonionic mixed surfactant stabilized water-in-oil microemulsions for active ingredient in vitro sustained release. J Surfact Deterg 19: 49-56. https://doi.org/ 10.1007/s11743-015-1753-z.

Zheng H, Mao L, Yang J, Zhang C, Miao S, Gao Y. 2020. Effect of oil content and emulsifier type on the properties and antioxidant activity of sea buckthorn oil-in-water emulsions. J Food Qual 2020: 8. https://doi.org/10.1155/2020/1540925.

Zhu YY, Kiran Thakur K, Feng JY, et al. 2020. B-vitamin enriched fermented soymilk: A novel strategy for soy-based functional foods development. Trends Food Sci Technol 105: 43-55. https:// doi.org/10.1016/j.tifs.2020.08.019.

Cite this article as: Kaltsa O, Alibade A, Batra G, Bozinou E, Makris DP, Lalas SI. 2021. Fortification of chocolate using Moringa oleifera extract encapsulated in microemulsions. OCL 28: 38. 